\title{
The association of family and peer factors with tobacco, alcohol, and marijuana use among Chilean adolescents in neighborhood context
}

This article was published in the following Dove Press journal:

Substance Abuse and Rehabilitation

2 September 201 I

Number of times this article has been viewed

\author{
Pilar Horner' \\ Andy Grogan-Kaylor ${ }^{2}$ \\ Jorge Delva ${ }^{2}$ \\ Cristina B Bares ${ }^{3}$ \\ Fernando Andrade ${ }^{4}$ \\ Marcela Castillo ${ }^{5}$ \\ 'School of Social Work, Michigan State \\ University, East Lansing, MI, USA; \\ ${ }^{2}$ School of Social Work, University \\ of Michigan, Ann Arbor, MI, USA; \\ ${ }^{3}$ School of Social Work, Virginia \\ Commonwealth University, Richmond, \\ VA, USA; ${ }^{4}$ School of Education, \\ University of Michigan, Ann Arbor, \\ MI, USA; ${ }^{5}$ nstituto de Nutrición y \\ Tecnología de los Alimentos (INTA), \\ Universidad de Chile, Santiago, Chile
}

Correspondence: Pilar Horner

I 20 Baker Hall, School of Social Work,

East Lansing, MI 48824, USA

Tel +l 5 I7 3530775

Fax +I 5173533038

Email phorner@msu.edu

\begin{abstract}
Research on adolescent use of substances has long sought to understand the family factors that may be associated with use of different substances such as alcohol, tobacco, and marijuana. However, scant attention has been focused on these questions in Latin American contexts, despite growing concerns about substance use among Latin American youth. Using data from a sample of 866 Chilean youth, we examined the relationship of family and neighborhood factors with youth substance abuse. We found that in a Latin American context, access to substances is an important predictor of use, but that neighborhood effects differ for marijuana use as opposed to cigarettes or alcohol. Age of youth, family and peer relationships, and gender all play significant roles in substance use. The study findings provide additional evidence that the use of substances is complex, whereby individual, family, and community influences must be considered jointly to prevent or reduce substance use among adolescents.
\end{abstract}

Keywords: substance use, adolescence, international, peers

\section{Introduction}

Considerable research has been carried out examining the relationship of family factors with substance use. Healthy family functioning and adequate levels of involvement between adolescents and their parents are family characteristics that act as protective factors against the use of substances. For example, low levels of family involvement have been linked to a number of problem behaviors during adolescence, including marijuana use..$^{1-3}$ In addition, various studies support the role that parental monitoring plays in attenuating adolescent delinquency and drug use. ${ }^{4-7}$ Research indicates that parents who think it is important to know where their children are and who spend time with their children are less likely to have adolescents who use substances ${ }^{8,9}$ Increases in levels of parental warmth have also been found to be associated with a decrease in adolescent alcohol use and to have an indirect relationship via the parent-child relationship to decrease substance use..$^{10}$ Conversely, neglectful parenting has been found to be significantly associated with increases in adolescent substance use. ${ }^{11}$

Aside from the family, the peer system plays a critical role in adolescents' substance use. Adolescents who experience low levels of parental monitoring have been shown to have an increased risk of affiliating with delinquent peers ${ }^{12,13}$ and engaging in rule-breaking behaviors. ${ }^{14}$ Youth who have multiple risk factors are vulnerable to having their negative behavior reinforced by the peer group who values these same behaviors. ${ }^{15}$ Peer relationships characterized by having friends who are involved in illegal or rule-breaking activities and who live closer to friends who use drugs have been found to increase rates of substance use during adolescence. ${ }^{16-18}$ Similar findings 
have been reported using samples from different parts of the world. ${ }^{19}$

Research on structural forces, such as neighborhoods, has also recently added to the literature on predicting youth substance use. The importance of considering neighborhood factors when looking at youth behavioral and socioemotional outcomes for substance use is reflected by a growing tradition in neighborhood research. Recent research suggests that neighborhoods can indeed influence substance use and misuses. ${ }^{20-22}$ Still, much work remains on discovering the mechanisms through which neighborhood effects have an impact on outcomes for adolescent behaviors.

Research in this area has very seldom used Latin American samples. Moreover, studies that explore the association between parenting and neighborhood characteristics and adolescents' drug use in this region of the world are scarce but may show similar patterns to non-Latin American samples. For example, one Chilean study indicates that adolescents who perceive their families as dysfunctional are at greater risk of using substances including marijuana. ${ }^{23}$ The overall dearth of empirical research on Latin American adolescents is unfortunate because of growing concerns about substance use among Latin American youth. According to the 2009 UN World Drug Report as well as studies conducted by the Inter-American Drug Abuse Control Commission of the Organization of American States, and by several Latin American countries, illicit drug use in Latin America in the past $10-15$ years has been stable or on the rise. ${ }^{24-28}$

Chile is a unique case to consider: its economy is one of the most stable in Latin America; it has a strong recent democratic history (the exception being the Pinochet dictatorship era); and it leads Latin America in income per capita. Despite its significant progress, Chile appears to be experiencing a rise in illicit drug consumption. In a recent study of nine South American countries, Chile ranked highest in marijuana use, ${ }^{27}$ and Chilean youth had the highest smoking prevalence of youth in any of the study countries. ${ }^{29}$ Over $50 \%$ of Chilean children, 14 years or younger, have smoked cigarettes, indicating that Chilean youth begin smoking at young ages. This early onset of smoking makes Chilean youth susceptible to nicotine dependence, heavy smoking, tobacco-related death, ${ }^{30}$ and involvement in more serious illicit drugs. Chile appears to be one of the latest countries experiencing a rise in illicit drug trafficking and consumption with grave implications for its youth. ${ }^{31}$ In the same study, Chile also ranked highest in tobacco, marijuana, and coca paste use and was tied in terms of cocaine use with Argentina. Furthermore, recent drug trafficking is perceived to be more highly prevalent in poor neighborhoods compared with more affluent neighborhoods..$^{32}$ More recently, these neighborhoods have also experienced an increase in gangs fighting for control of drug distribution and other criminal activities. If this trend of neighborhood deterioration continues, it is entirely plausible that Chile's democratic institutions could be threatened in similar ways to those in Colombia and Mexico.

Understanding how the perspectives of individual and structural factors impact differing cultural, racial, and ethnic groups greatly enhances our knowledge base and implications for policy interventions in different populations. This paper focuses on one Latin American country, Chile, and specifically one cohort of youth all living in the greater metropolitan area of the capital city of Santiago.

Very few studies of Chilean families exist that simultaneously examine the variety of individual, parenting, and neighborhood characteristics that are likely to have an effect on whether adolescents use cigarettes, alcohol, or marijuana. A comprehensive literature review of published studies of substance use among youth in Chile found that none of those publications included information on families or neighborhood effects. ${ }^{33-37}$ On the other hand, unpublished reports produced by governmental organizations, including the Organization of American States Inter-American Drug Abuse Control Commission, produce very informative reports looking at substance use among adolescents, but these findings are limited to bivariate analyses. To fill this gap in our knowledge, in this paper we present findings using data from the first wave of an ongoing longitudinal study of adolescents in Santiago, Chile, in which individual, family, and neighborhood effects were examined to understand their association with Chilean adolescent cigarette, alcohol, and marijuana use.

\section{Methods}

In 2008-2010, 1035 youth from Santiago, Chile, completed the first part of a two-part assessment funded by the National Institute on Drug Abuse scheduled 2 years apart that consisted of a 2-hour interviewer-administered questionnaire with comprehensive questions on drug use and a range of individual, familial, and contextual variables. The measures were translated and back translated, and then the measures were pilot tested with the population under investigation prior to conducting the study.

For this paper, 866 12-17 year olds from municipalities of mid-to-low socioeconomic status (SES) that had completed data on all of the variables were included in the present study. Not all participants had data on all the 
variables that this paper examines, therefore we could not use the total 1035 youth who had been interviewed as part of this research study. Interviews were held at the Institute of Nutrition and Technology for Alimentation (Instituto de Nutrición y Tecnología de los Alimentos [INTA]), which is a research center of the University of Chile. Youth participants were recruited from a convenience sample of 1200 youth who several years earlier had participated in a study of iron and nutritional status at INTA. ${ }^{38}$ All interviews were conducted in Spanish, in private rooms at INTA, by a team of six psychologists trained on the administration of standardized questionnaires.

Informed consent was collected from each youth before the start of their interviews. This research study was approved by the Institutional Review Board at the University of Michigan.

\section{Measures}

\section{Dependent measurements}

Youth who indicated that they had smoked cigarettes or drank alcohol in the past 30 days from when the interview was conducted were asked follow-up questions about the consumption of these substances. In this study, the three dependent variables were the average number of cigarettes and alcohol the youth had consumed in the past 30 days and the number of occasions that youth consumed marijuana in the same period. Youth were asked, "On average, how many cigarettes have you smoked on a daily basis in the past 30 days? (If you smoke infrequently think of a typical day)". For the alcohol question, youth were asked, "On those days that you drank alcohol in the past 30 days, how many drinks (wine, beer, liquor) have you usually had? (If you drink infrequently, think of a typical day)". The dependent variable of marijuana use consisted of the number of occasions youth had smoked marijuana in the past 30 days based on the question "On how many occasions have you used marijuana during the past 30 days?" with response categories of "never", "1-2 occasions", "3-5 occasions", "6-9 occasions", "10-19 occasions", "20-39 occasions", and "40 or more occasions".

Predictors consisted of a number of variables that assessed individual, family and peers, and neighborhood characteristics. In the following we describe each variable.

\section{Independent measurements}

Age and sex were assessed based on the adolescents' selfreports, and family SES was assessed based on the parents' reports. SES was based on the Graffar scale, ${ }^{39}$ which is considered an appropriate assessment of SES in developing countries and has been used frequently in research in Chile. ${ }^{38,40,41}$ The SES instrument contained 13 questions, which were utilized to obtain a composite score of SES. Questions included items such as "total number of adults in the same house", "type of job by head of household", "father's education", and "type of sewage accommodations".

Adolescents' behavior problems were assessed by the Youth Self Report (YSR). ${ }^{42}$ The YSR is widely used internationally and is one of the most commonly used assessment tools for problem behaviors among children and adolescents. ${ }^{42}$ Numerous studies have shown the measures to have adequate reliability and validity. ${ }^{43-45}$ The YSR instrument is appropriate for children or adolescents between 11 and 18 years old to complete as a self-administered questionnaire. The YSR yields separate Internalizing and Externalizing scales that are divided into six subscales. For our analyses, we used the YSR total score, which aggregates the internalizing and externalizing scales into one overall scale. Higher scores represent more behavioral problems. The Cronbach's alpha for this measure was 0.92 .

The variable measuring how difficult it would be to get the substance (alcohol, marijuana, cigarettes) was taken from the drug use opportunities scale of the Monitoring the Future study. ${ }^{46}$ Respondents were asked, "How difficult do you think it would be to get each of the following types of substances, if you wanted some?" Then we measured three substances: cigarettes, alcohol, and marijuana. For each of the three substances, respondents could answer with one of the following responses: "Very easy", "Easy", "Difficult", "Very difficult", "I would not be able to", "Don't know", or "I don't know the substance". The Cronbach's alpha for this measure was 0.84 .

\section{Family and peer variables}

The family and peer variables consisted of measures that assessed family involvement in the youth's life, parental monitoring, mother and father parenting behaviors, peer perception of the substance as disapproval, peer drug use, and peer pressure to use.

\section{Family involvement}

Adolescents' self-reports of their family involvement was assessed through five items from the Child Health and Illness Profile-Adolescent Edition which has previously been validated with a Spanish sample of adolescents, ${ }^{47-49}$ The stem question, "Thinking about your family, about how many days in the past 4 weeks did your parents or other adults in 
your family ...", was followed by items such as "spend time with you doing something fun", "eat meals with you", and "talk with you or listens to your opinions and ideas". The response categories were " $1=$ No days", " $2=1$ to 3 days", " $3=4$ to 6 days", " $4=7$ to 14 days", and " $5=15$ to 28 days". Higher scores indicate greater levels of family involvement. Cronbach's alpha for this variable was 0.73 .

\section{Parental monitoring}

Adolescents' self-reports of how much parental monitoring they had received were assessed by ten questions used in a National Institute of Child Health and Human Development Study of Early Child Care and Youth Development. Example items included "If your mom/dad or guardian are not home, how often do you leave a note for them about where you are going?" and "How often, before you go out, do you tell your $\mathrm{mom} / \mathrm{dad}$ or guardian when you will be back". The response categories for these questions were " 1 = All of the time", "2 = Most times", "3 = Sometimes", "4 = Hardly ever", and " $5=$ Never". After reverse coding all of the items, a composite score was created by adding the responses to the ten questions with higher scores representing more parental monitoring. Cronbach's alpha for this variable was 0.67 .

\section{Mother and father parenting behaviors}

Adolescent perceptions of parenting behaviors were assessed separately for the mother and father by asking 17 questions from the Parental Warmth, Support and Hostility measure. ${ }^{50}$ This questionnaire asked the adolescent to report on the extent to which parents engage in a continuum of more to less positive parenting behaviors. ${ }^{50}$ Examples of items included "How often does your (mother/father) let you know (she/he) really cares about you?”, “... listens carefully to your point of view?”, “... gets angry at you?”, “... boss you around a lot?”, “... insult or swear at you?”, with response categories being " 1 = Never", " $2=$ Sometimes", "3 = Often", and " 4 = Always". Items were added to create a composite score for each of the mother and father scales. Higher scores represent more positive relationships with each of the parents or guardians. Cronbach's alpha for the mother scale was 0.89 and for father was 0.89 , respectively.

\section{Peer perception/disapproval of drug use}

"Peer perception about drug use" was measured with the peer perception about drug use scale. ${ }^{51}$ This scale was comprised of 13 items to which the study participant could respond "Not Disapprove", "Disapprove", or "Strongly Disapprove". Higher scores indicated higher levels of disapproval of drug use by peers. Specific items asked about things like "How do you think your CLOSE FRIENDS feel (or would feel) about YOU smoking one or more packs of cigarettes per day" and "How do you think your CLOSE FRIENDS feel (or would feel) about YOU using marijuana regularly". The Cronbach's alpha for this measure was 0.92 .

\section{CHIP - peer drug use}

"Peer drug use" was taken from the Child Health and Illness Profiles (CHIP) scale. ${ }^{52,53}$ The "peer drug use" subset scale was comprised of nine items to which the study participant could respond "none", "a few", "some", "most", or "all". Specific items asked about things like "How many of your friends would you estimate smoke cigarettes", and "How many of your friends would you estimate get drunk at least once a week". Higher scores indicated a higher number of friends who use drugs. The Cronbach's alpha for this measure was 0.86 .

\section{CHIP - peer pressure to use drugs}

"Peer pressure to use drugs" was taken from the CHIP scale. ${ }^{48,49}$ This subset scale to measure peer pressure to use drugs was comprised of four items to which the study participant could respond "none", "a little", "some", or "a lot". Specific items asked about things like "How much pressure do you feel from your friends and schoolmates to smoke cigarettes" and "How much pressure do you feel from your friends and schoolmates to drink alcoholic beverages". Higher scores indicated a greater pressure from friends to use substances. The Cronbach's alpha for this measure was 0.88 .

\section{Neighborhood variables}

Four "neighborhood variables" were taken from the National Survey of American Life: Adolescent Questionnaire. ${ }^{54}$ The first variable was based on the question "How often do your parents get together with any of your neighbors; that is, either visiting at each other's homes or going places together?" Respondents could answer: "Nearly every day (four or more times a week)", "At least once a week (one to three times)", "A few times a month (two to three times)", "At least once a month", "A few times a year", "Never". The second variable was based on the question "How often are there problems with muggings, burglaries, assaults or anything else like that in your neighborhood?" To which the respondent could answer: "very often", "fairly often", "not too often", "hardly ever", or "never". The third variable was based on the question "How much of a problem is the selling and use of drugs in your neighborhood?" 
to which the respondent could answer "very serious", "fairly serious", "not too serious", "not serious at all", or "never". The fourth variable was based on the question "During the past 12 months, how often have you seen people selling illegal drugs in your neighborhood?" to which the respondent could answer "almost every day", "at least once a week", "once or twice a month", "a few times a year", or "never".

\section{Analysis}

Our analysis examined the predictors of use of three different substances: cigarettes, alcohol, and marijuana. In each case, we examined the predictors of the amount of a given substance within the last 30 days. Because the dependent variables represented the count of specific behaviors, we employed negative binomial regression models appropriate for a count dependent variable. ${ }^{55}$ Coefficients from a negative binomial model may be exponentiated $\left(\mathrm{e}^{\beta}\right)$ to provide intuitively understandable parameters. Such exponentiated coefficients may be interpreted as effects on the "incidence rate ratio" $" 56$ of the event of interest. Variables were added to the model in stages. For each dependent variable, a first model examined the relationship of individual factors with the use of that substance. A second model then added a block of variables at the level of family and peers. A final model included not only individual and family and peer variables, but also neighborhood variables.

\section{Results}

Descriptive statistics are shown in Table 1. Out of the 1866 youth, 52\% were boys, and the average age was 14.5 years. Youth who indicated they had smoked once in their lives $(n=327)$ were asked how many cigarettes they had smoked in the last 30 days. The average number of cigarettes smoked was $0.60 \pm 1.55$ (min-max: 0-12). Youth who indicated they had drunk alcohol in their lives $(n=388)$ were asked how many drinks they had imbibed in the last 30 days. The average number of drinks was $0.50 \pm 1.31$ (min-max: 0-12); youth who reported smoking marijuana ever in their lives $(n=139)$ were asked to report the number of occasions they had smoked in the past 30 days. The average number of occasions of smoking marijuana was $0.10 \pm 0.50$ (min-max: 0-6).

Results of the negative binomial regression for cigarettes, for alcohol, and for marijuana are shown in Tables 2-4, respectively. In the model of cigarette smoking with only individual variables, increases in respondent age and YSR score were both associated with increases in smoking. Increases in perceived difficulty of getting cigarettes were associated with decreases in cigarette smoking. In the model with family and peer variables, age, YSR, and difficulty of getting cigarettes remained statistically significant. Additionally, increases in parental monitoring were associated with decreases in cigarette

Table I Descriptive statistics $(\mathrm{N}=866)$

\begin{tabular}{|c|c|c|c|c|}
\hline Variable & Mean & Standard deviation & Minimum & Maximum \\
\hline \multicolumn{5}{|l|}{ Individual } \\
\hline Male & 1.48 & 0.50 & 0 & I \\
\hline Age & 14.49 & 1.50 & 11.92 & 17.83 \\
\hline YSR & 44.38 & 19.47 & 3 & 121 \\
\hline Graffar (SES) & 32.85 & 6.74 & 18 & 58 \\
\hline How difficult to get substance & 1.88 & 1.16 & 1 & 5 \\
\hline \multicolumn{5}{|l|}{ Family/peers } \\
\hline Parent monitoring & 27.47 & 5.34 & 7 & 35 \\
\hline Family involvement & 18.64 & 4.24 & 5 & 25 \\
\hline Relationship with mother & 55.31 & 8.41 & 23 & 68 \\
\hline Relationship with father & 54.21 & 9.06 & 18 & 68 \\
\hline Peer perception/disapproval & 35.29 & 5.19 & 13 & 39 \\
\hline Peer substance use & 15.23 & 5.78 & 8 & 41 \\
\hline Peer pressure to use drugs & 4.86 & 2.18 & 4 & 16 \\
\hline \multicolumn{5}{|l|}{ Drug use } \\
\hline Cigarette & 0.60 & 1.55 & 0 & 12 \\
\hline Alcohol & 0.53 & 1.32 & 0 & 12 \\
\hline Marijuana & 0.96 & 0.51 & 0 & 6 \\
\hline \multicolumn{5}{|l|}{ Neighborhood } \\
\hline Parents get together with neighbors & 1.53 & I.7| & 0 & 5 \\
\hline Muggings, burglaries, assaults & 2.83 & 1.13 & I & 5 \\
\hline Selling and using drugs & 3.69 & 1.30 & 1 & 5 \\
\hline Selling and using drugs in the past 12 months & 2.44 & 1.62 & I & 5 \\
\hline
\end{tabular}

Abbreviation: SES, socioeconomic status. 
Table 2 Predictors of cigarette use in the past 30 days: results from negative binomial regression analyses

\begin{tabular}{|c|c|c|c|}
\hline Variable & Individual factors & Family and peer factors & Neighborhood factors \\
\hline Female gender & $\mathrm{I} .122$ & 1.333 & $1.373^{\mathrm{a}}$ \\
\hline Age & $1.638^{\mathrm{b}}$ & $1.384^{\mathrm{b}}$ & $1.354^{\mathrm{b}}$ \\
\hline SES & 1.013 & 1.007 & 1.006 \\
\hline YSR total score & $1.019^{b}$ & 1.007 & 1.007 \\
\hline How difficult to get substance & $0.385^{b}$ & $0.447^{\mathrm{b}}$ & $0.447^{\mathrm{b}}$ \\
\hline Relationship with mother & & 1.005 & 1.005 \\
\hline Relationship with father & & 0.987 & 0.986 \\
\hline Parental monitoring & & $0.962^{c}$ & $0.962^{c}$ \\
\hline Family involvement & & 0.984 & 0.983 \\
\hline Peer perception/disapproval & & 0.994 & 0.992 \\
\hline Peer substance use & & $1.108^{\mathrm{b}}$ & $\mathrm{I} .109^{\mathrm{b}}$ \\
\hline Peer pressure to use & & $0.931^{\mathrm{a}}$ & 0.935 \\
\hline Parents get together with neighbors & & & 0.922 \\
\hline Muggings, burglaries, assaults in your neighborhood & & & $0.827^{c}$ \\
\hline Selling and using drugs in your neighborhood & & & 0.981 \\
\hline Selling and using drugs in the past 12 months & & & $\mathrm{I} .14 \mathrm{I}^{\mathrm{c}}$ \\
\hline \multicolumn{4}{|l|}{ in your neighborhood } \\
\hline Constant & $0.000^{\mathrm{b}}$ & $0.008^{\mathrm{b}}$ & $0.017^{\mathrm{b}}$ \\
\hline \multicolumn{4}{|l|}{ Ln (alpha) } \\
\hline Constant & $3.100^{\mathrm{b}}$ & $2.532^{\mathrm{b}}$ & $2.453^{\mathrm{b}}$ \\
\hline \multicolumn{4}{|l|}{ Statistics } \\
\hline $\mathrm{N}$ & 866 & 866 & 866 \\
\hline Log likelihood & $-7|2.36|$ & -686.945 & -682.399 \\
\hline
\end{tabular}

Notes: ${ }^{a} p<0.05 ;{ }^{b} p<0.001 ; ~ c p<0.01$.

Abbreviations: SES, socioeconomic status; YSR, Youth Self Report.

Table 3 Predictors of alcohol use in the past 30 days: results from negative binomial regression analyses

\begin{tabular}{|c|c|c|c|}
\hline Variable & Individual factors & Family and peer factors & Neighborhood factors \\
\hline Female gender & $0.557^{\mathrm{a}}$ & $0.623^{a}$ & $0.600^{\mathrm{a}}$ \\
\hline Age & $1.475^{\mathrm{a}}$ & $1.305^{\mathrm{a}}$ & $1.308^{\mathrm{a}}$ \\
\hline SES & 0.984 & $0.979^{b}$ & $0.975^{c}$ \\
\hline YSR total score & $1.019^{a}$ & 1.003 & 1.004 \\
\hline How difficult to get substance & $0.600^{\mathrm{a}}$ & $0.727^{a}$ & $0.723^{\mathrm{a}}$ \\
\hline Relationship with mother & & 0.995 & 0.997 \\
\hline Relationship with father & & 0.985 & $0.984^{b}$ \\
\hline Parental monitoring & & $0.95 I^{a}$ & $0.954^{a}$ \\
\hline Family involvement & & 0.999 & 0.993 \\
\hline Peer perception/disapproval & & 0.977 & 0.977 \\
\hline Peer substance use & & $1.093^{\mathrm{a}}$ & $1.095^{\mathrm{a}}$ \\
\hline Peer pressure to use & & 0.983 & 0.991 \\
\hline Parents get together with neighbors & & & 1.020 \\
\hline Muggings, burglaries, assaults in your neighborhood & & & $0.818^{c}$ \\
\hline Selling and using drugs in your neighborhood & & & 0.992 \\
\hline Selling and using drugs in the past 12 months & & & 1.070 \\
\hline \multicolumn{4}{|l|}{ in your neighborhood } \\
\hline Constant & $0.006^{\mathrm{a}}$ & 0.292 & $0.44 I$ \\
\hline \multicolumn{4}{|l|}{ Ln (alpha) } \\
\hline Constant & $2.3285^{\mathrm{a}}$ & $1.540^{\mathrm{a}}$ & $1.496^{c}$ \\
\hline \multicolumn{4}{|l|}{ Statistics } \\
\hline $\mathrm{N}$ & 866 & 866 & 866 \\
\hline Log likelihood & -706.782 & -664.602 & -661.032 \\
\hline
\end{tabular}

Notes: ${ }^{a} p<0.001$; ${ }^{b} p<0.05 ;{ }^{c p}<0.01$.

Abbreviations: SES, socioeconomic status; YSR, Youth Self Report. 
Table 4 Predictors of marijuana use in the past 30 days: results from negative binomial regression analyses

\begin{tabular}{|c|c|c|c|}
\hline Variable & Individual factors & Family and peer factors & Neighborhood factors \\
\hline Female gender & 1.080 & $\mathrm{I} .85 \mathrm{I}$ & $2.112^{\mathrm{a}}$ \\
\hline Age & $1.932^{\mathrm{b}}$ & $1.710^{\mathrm{b}}$ & $1.693^{b}$ \\
\hline SES & 1.005 & 0.997 & 1.005 \\
\hline YSR total score & $1.022^{c}$ & 1.011 & 1.009 \\
\hline How difficult to get substance & $0.382^{\mathrm{b}}$ & $0.566^{\mathrm{b}}$ & $0.588^{c}$ \\
\hline Relationship with mother & & 1.009 & 1.012 \\
\hline Relationship with father & & 0.985 & 0.983 \\
\hline Parental monitoring & & $0.902^{\mathrm{b}}$ & $0.910^{\mathrm{b}}$ \\
\hline Family involvement & & $1.09 \mathrm{I}^{\mathrm{a}}$ & $\left.1.09\right|^{\mathrm{a}}$ \\
\hline Peer perception/disapproval & & $0.911^{b}$ & $0.909^{b}$ \\
\hline Peer substance use & & $1.118^{b}$ & $1.119^{b}$ \\
\hline Peer pressure to use & & 0.901 & 0.900 \\
\hline Parents get together with neighbors & & & 0.983 \\
\hline Muggings, burglaries, assaults in your neighborhood & & & 1.213 \\
\hline Selling and using drugs in your neighborhood & & & 0.789 \\
\hline Selling and using drugs in the past 12 months in your neighborhood & & & 1.103 \\
\hline Constant & $0.000^{\mathrm{b}}$ & $0.000^{\mathrm{b}}$ & $0.000^{\mathrm{b}}$ \\
\hline \multicolumn{4}{|l|}{ Ln (alpha) } \\
\hline Constant & $4.303^{b}$ & $2.077^{c}$ & $1.960^{\mathrm{a}}$ \\
\hline \multicolumn{4}{|l|}{ Statistics } \\
\hline $\mathrm{N}$ & 793 & 793 & 793 \\
\hline Log likelihood & -189.217 & -164.347 & -163.162 \\
\hline
\end{tabular}

Notes: ${ }^{a} P<0.05$; b $P<0.00$ I; $c P<0.0$ I.

Abbreviations: SES, socioeconomic status; YSR, Youth Self Report.

usage, while increases in peer drug use were associated with increases in cigarette smoking. Interestingly, increased peer pressure to use drugs was associated with decreased cigarette smoking. A final model added neighborhood factors. All prior factors remained statistically significant. Of neighborhood factors, only "muggings, burglaries and assaults" were associated with cigarette use, and increases in such neighborhood problems were associated with decreases in cigarette smoking.

There were also interesting results for the predictors of alcohol use. As before, a first model estimated the relationship of individual factors with alcohol use. Youth, gender, and age were associated with alcohol use. Females were less likely to use alcohol than males. Alcohol use also increased with the age of the youth. Behavior problems, as measured by the YSR, were positively associated with alcohol use. A perception of greater difficulty of getting alcohol was associated with decreased alcohol use. When family and peer variables were added to the models, most of these variables retained their statistical significance. However, YSR scores were no longer statistically significant in a model containing family and peer variables. Some family and peer variables showed a relationship with alcohol use. Increased parental monitoring was associated with decreased alcohol use. Increased peer pressure to use drugs was also associated with increased alcohol use. When neighborhood variables were added to the model, all statistically significant variables from the prior model retained their statistical significance. Of the neighborhood variables, only "muggings, burglaries and assaults" were statistically significant. As with cigarettes, perceptions of neighborhood violence such as muggings, burglaries, and assaults were associated with decreases in alcohol use.

A final set of models were used to examine the predictors of marijuana usage. Of the individual level factors, only youth age and perception of difficulty of getting marijuana were associated with marijuana usage. Older youth were more likely to use marijuana, while those perceiving more difficulty in obtaining marijuana were less likely to use marijuana. A second model added family and peer variables to the model. Increases in parental monitoring were associated with decreases in marijuana usage. Increases in family involvement were associated with increases in marijuana usage. Increases in peer disapproval were associated with decreases in marijuana usage, and increases in peer drug use were associated with increased marijuana consumption. A final model added neighborhood variables to the model. No neighborhood variables had a statistically significant relationship with marijuana usage. 


\section{Discussion}

The study findings provide additional evidence, this time in the Latin American country of Chile, that the predictors of substance use are multifaceted, whereby individual, family, and community influences must be considered jointly to prevent or reduce substance use among adolescents. In addition, the findings indicate the importance of studying substance use outcomes separately because some factors are related to some substances differently. Strategies that would seek to prevent or decrease the consumption of substances must be mindful of the particular factors associated with use of that substance. Chile is a developing country with a strong market-driven economy and a respectable democratic history; its rise in illicit drug consumption is troubling. As with many Latin American cultures, families in Chile have strong ties, and the findings from our analysis that parental monitoring displayed a consistent relationship with reduced substance use across all of the substances suggests that promotion of parental monitoring skills could be an important part of intervention strategies. Similarly, our measure of peer substance use was found to be consistently and positively correlated with increased drug use. Thus, reduction of association with substance using peers presents a key potential prevention strategy.

Given the high rate of substance use among Chilean adolescents, our findings regarding the relationship of neighborhood factors with substance use outcomes are particularly intriguing. For example, one of the main findings of this study is that neighborhood levels of crime are associated with adolescents' use of cigarettes and alcohol. Further, having seen drugs being used and sold within the past 12 months is positively correlated with cigarette use. Thus, neighborhood-based strategies, particularly those focused on the reduction of neighborhood crime, may have beneficial consequences with regard to adolescent substance use. Interestingly, however, our findings do not indicate a relationship between neighborhood factors and levels of marijuana use. One reason for these findings may be that marijuana is an illicit drug and is not as socially acceptable among Chilean youth, whereas cigarette smoking and drinking are more culturally accepted. Neighborhood or community factors may thus be more strongly related to the use of culturally acceptable, prevalent or normative substances than they are to culturally proscribed substances. This finding suggests that in Chile, strategies aimed at the reduction of marijuana use could be most profitably focused on family and peer factors rather than neighborhood factors.
Although our work contributes to the issues of peer, family, and neighborhood impacts, this study does have some notable limitations. For one, the data used in these analyses were based upon youth self-report; the study findings may yet be more robust with stronger data collection methods. Also these data are cross-sectional and thus the usual caveat about refraining from making strong causal attributions to these results is applicable. Notwithstanding these limitations, this work does point to some important conclusions. First, this study provides an important contribution to how substance use functions within the context of peers, family, and neighborhoods in Santiago, Chile, and there is very little research that focuses on Latin American communities. Secondly, the results suggest that cigarettes, alcohol, and marijuana use function differently within the adolescent population and thus while some intervention components may cut across substances, others may be more effective if they are substance specific.

We underscore the importance of approaching the issue of youth substance use in Latin America with a multifaceted lens. Chile's political and economic stability have raised its reputation in the United States and the world. With Chile aligning itself more with the Westernized geopolitical sphere, its youth may become more susceptible to increasing pressures and access to substance use. We suggest that the growing use of social media, rapidly linking Chile to outside influences, may have potential deleterious effects on how youth in Chile socialize and engage in risky behaviors. For example, a recent New York Times article highlighted a new trend among Chilean youth to engage in "ponceos" or public orgies fueled by alcohol and illicit drugs. ${ }^{57}$ These gatherings are arranged through social media, and the random use of drugs and engagement in public sex is a severely dangerous and troublesome trend. Understanding the complex relationship of youth and substance use thus requires research and interventions that fully explore the complexity of lived realities in Latin America in general, and Chile in particular. This study, though limited in its scope, begins to address this need and suggests that more complex research models be applied for the necessary and culturally appropriate youth substance use intervention and prevention strategies.

\section{Acknowledgments}

We extend a sincere appreciation to the families in Chile for their participation in this study, without whom this project could not have been possible. This study received support from the US National Institute on Drug Abuse (R01 DA021181) and the Vivian A and James L Curtis School of Social Work Research and Training Center. 


\section{Disclosure}

The authors report no conflicts of interest in this work.

\section{References}

1. Ary DV, Duncan TE, Biglan A, Metzler CW, Noell JW, Smolkowski K. Development of adolescent problem behavior. J Abnorm Child Psychol. 1999;27(2):141-150.

2. Caldwell RM, Beutler LE, An Ross S, Clayton Silver N. Brief report: an examination of the relationships between parental monitoring, selfesteem and delinquency among Mexican American male adolescents. J Adolesc. 2006;29(3):459-464.

3. Hoffmann JP. The effects of family structure and family relations on adolescent marijuana use. Int J Addict. 1995;30(10):1207-1241.

4. Pettit GS, Laird RD, Dodge KA, Bates JE, Criss MM. Antecedents and behavior-problem outcomes of parental monitoring and psychological control in early adolescence. Child Dev. 2001;72(2):583-598.

5. Chilcoat HD, Anthony JC. Impact of parent monitoring on initiation of drug use through late childhood. J Am Acad Child Adolesc Psychiatry. 1996;35(1):91-100.

6. Benjet C, Borges G, Medina-Mora ME, et al. Drug use opportunities and the transition to drug use among adolescents from the Mexico City Metropolitan Area. Drug Alcohol Depend. 2007;90(2-3):128-134.

7. Parker JS, Benson MJ. Parent-adolescent relations and adolescent functioning: self-esteem, substance abuse, and delinquency. Adolescence. 2004;39(155):519-530.

8. Dishion T, Loeber R. Adolescent marijuana and alcohol use: the role of parents and peers revisited. Am J Drug Alcohol Abuse. 1985;11(1): $11-15$.

9. Latendresse SJ, Rose RJ, Viken RJ, Pulkkinen L, Kaprio J, Dick D. Parenting mechanisms in links between parents' and adolescents' alcohol use behaviors. Alcohol Clin Exp Res. 2008;32(2):322-330.

10. Mogro-Wilson C. The influence of parental warmth and control on Latino adolescent alcohol use. Hisp J Behav Sci. 2008;30(1):89-105.

11. Chassin L, Presson CC, Rose J, Sherman SJ, Davis MJ, Gonzalez JL. Parenting style and smoking-specific parenting practices as predictors of adolescent smoking onset. J Pediatr Psychol. 2005;30(4): 333-344.

12. Dishion TJ, Capaldi D, Spracklen KM, Li F. Peer ecology of male adolescent drug use. Dev Psychopathol. 1995;7(04):803-824.

13. Dishion TJ, Loeber R. Adolescent marijuana and alcohol use: the role of parents and peers revisited. Am J Drug Alcohol Abuse. 1985; 11(1-2):11-25.

14. Griffin KW, Botvin GJ, Scheier LM, Diaz T, Miller NL. Parenting practices as predictors of substance use, delinquency, and aggression among urban minority youth: moderating effects of family structure and gender. Psychol Addict Behav. 2000;14(2):174-184.

15. Dishion TJ, McCord J, Poulin F. When interventions harm: peer groups and problem behavior. Am Psychol. 1999;54(9):755.

16. Hawkins JD, Catalano RF, Miller JY. Risk and protective factors for alcohol and other drug problems in adolescence and early adulthood: implications for substance abuse prevention. Psychol Bull. 1992; 112(1):64.

17. Ennett ST, Bauman KE, Hussong A, et al. The peer context of adolescent substance use: findings from social network analysis. $J$ Res Adolesc. 2006;16(2):159-186.

18. Ferguson CJ, Meehan DC. With friends like these ...: peer delinquency influences across age cohorts on smoking, alcohol and illegal substance use. Eur Psychiatry. 2011;26(1):6-12.

19. Kiesner J, Poulin F, Dishion TJ. Adolescent substance use with friends: moderating and mediating effects of parental monitoring and peer activity contexts. Merrill Palmer Q (Wayne State Univ Press). 2010; 56(4):529.

20. Galea S, Ahern J, Vlahov D, et al. Income distribution and risk of fatal drug overdose in New York City neighborhoods. Drug Alcohol Depend. 2003;70(2):139-148.
21. Sampson RJ, Morenoff JD, Gannon-Rowley T. Assessing "neighborhood effects": social processes and new directions in research. Аnnu Rev Sociol. 2002;28:443-478.

22. Kulis S, Marsiglia FF, Sicotte D, Nieri T. Neighborhood effects on youth substance use in a southwestern city. Sociol Perspect. 2007; 50(2):273-301.

23. Santander S, Zubarew T, Santelices L, Argollo P, Cerda J, Borquez M. Influencia de la familia como factor protector de conductas de riesgo en excolares chilenos. Family influence as a protective factor against risk behaviors in Chilean adolescents. Revista médica de Chile. 2008; 136:317-324. Spanish.

24. United Nations on Drugs and Crime and the Inter-American Observatory on Drugs Inter-American Drug Abuse Control Commission; Informe subregional sobre uso de drogas en pobacion escolarizada; 2010.

25. Inter-American Drug Abuse Control Commission (CICAD). REDLA network identifies worrisome trends in drug use across Latin America. CICAD Observer [newsletter on the Internet]. 2008 [cited No. 1, Year 6/First Quarter 2008]. http://www.cicad.oas.org/oid/NEW/Information/ Observer/08_01/REDLA.asp. Accessed June 25, 2011.

26. United Nations Office on Drugs and Crime (UNODC). World Drug Report 2009. Vienna, Austria: UNODC; 2009.

27. United Nations Office on Drugs and Crime (UNODC). Youth and Drugs in South American Countries: a public policy challenge. Vienna, Austria: UNODC; 2006.

28. United Nations Office on Drugs and Crime (UNODC). Subregional System of Information and Research on Drugs in Argentina, Chile, Bolivia, Ecuador, Peru, and Uruguay: first comparative study on drug use and associated factors in the general population 15-64 years of age. Vienna, Austria: UNODC; 2008.

29. Inter-American Drug Abuse Control Commission (CICAD). Informe subregional sobre uso de drogas en población escolarizada. 2009. Available from: http://www.unodc.org/documents/peruandecuador/ Informes/Segundo_Subregional.pdf. Accessed June 25, 2011.

30. Prokhorov AV, Winickoff JP, Ahluwalia JS, et al. Youth tobacco use: a global perspective for child health care clinicians. Pediatrics. 2006; 118(3):e890-e903.

31. Blum RW, Nelson-Mmari K. The health of young people in a global context. J Adolesc Health. 2004;35(5):402-418.

32. CONACE. Octavio Estudio Nacional de Drogas en Población. Santiago, Chile: Gobierno de Chile, Ministerio del Interior; 2008.

33. Caris L, Anthony CB, Rios-Bedoya CF, Anthony JC. Behavioral problems and the occurrence of tobacco, cannabis, and coca paste smoking in Chile: evidence based on multivariate response models for school survey data. Drug Alcohol Depend. 2009;104(1-2):50-55.

34. Caris L, Varas M, Anthony CB, Anthony JC. Behavioral problems and tobacco use among adolescents in Chile. Rev Panam Salud Publica. 2003;14(2):84-90.

35. Caris L, Wagner FA, Rios-Bedoya CF, Anthony JC. Opportunities to use drugs and stages of drug involvement outside the United States: evidence from the Republic of Chile. Drug Alcohol Depend. 2009; 102(1-3):30-34.

36. Fuentealba R, Cumsille F, Araneda JC, Molina C. Consumption of licit and illicit drugs in Chile: results of the 1998 study and comparison with the 1994 and 1996 studies. Rev Panam Salud Publica. 2000;7(2):79-87. Spanish.

37. Martinez-Aguayo A, Araneda JC, Fernandez D, Gleisner A, Perez V, Codner E. Tobacco, alcohol, and illicit drug use in adolescents with diabetes mellitus. Pediatr Diabetes. 2007;8(5):265-271.

38. Lozoff B, De Andraca I, Castillo M, Smith JB, Walter T, Pino P. Behavioral and developmental effects of preventing iron-deficiency anemia in healthy full-term infants. Pediatrics. 2003;112(4): 846-854.

39. Graffar M. Une methode de classification sociale d'echantillons de population. Courrier. 1956;6(8):455-459.

40. Alvarez MD, Muzzo S, Ivanovic D. Escala para medición del nivel socioeconómico el área de la salud. Revista médica de Chile. 1985;133: 243-249. Spanish. 
41. Gahagan S, Yu S, Kaciroti N, Castillo M, Lozoff B. Linear and ponderal growth trajectories in well-nourished, iron-sufficient infants are unimpaired by iron supplementation. J Nutr. 2009;139(11):2106-2112.

42. Achenbach TM, Rescorla LA. Manual for the ASEBA School-Age: forms and profiles. Burlington, VT: University of Vermont, Research Center for Children, Youth, and Families; 2001.

43. Leung PW, Kwong SL, Tang CP, et al. Test-retest reliability and criterion validity of the Chinese version of CBCL, TRF, and YSR. J Child Psychol Psychiatry. 2006;47(9):970-973.

44. Ivanova MY, Achenbach TM, Rescorla LA, et al. The generalizability of the youth self-report syndrome structure in 23 societies. $J$ Consult Clin Psychol. 2007;75(5):729.

45. Rescorla L, Achenbach TM, Ivanova MY, et al. Epidemiological comparisons of problems and positive qualities reported by adolescents in 24 countries. J Consult Clin Psychol. 2007;75(2):351.

46. Johnston L, O’Malley P, Bachman J, Schulenberg J. Monitoring the future national results on adolescent drug use: overview of key findings, 2004 (NIH Publication No. 05-5726). Bethesda, MD: National Institute on Drug Abuse; 2005.

47. Alonso J, Urzola D, Serra-Sutton V, et al. Validity of the health profiletypes of the Spanish Child Health and Illness Profile - Adolescent Edition (CHIP-AE). Value Health. 2008;11(3):440-449.

48. Riley AW, Green BF, Forrest CB, Starfield B, Kang M, Ensminger ME. A taxonomy of adolescent health: development of the adolescent health profile-types. Med Care. 1998;36(8):1228-1236.

49. Riley AW, Forrest CB, Starfield B, Green B, Kang M, Ensminger M. Reliability and validity of the adolescent health profile-types. Med Care. 1998;36(8):1237-1248.
50. Conger RD, Ge X. Conflict and cohesion in parent-adolescent relations: changes in emotional expression from early to mid-adolescence. In: Cox M, Brooks-Gunn J, editors. Conflict and Cohesion in Families: causes and consequences. Mahwah, NJ: Erlbaum; 1999.

51. Johnston L, Bachman JG, O'Malley PM, Schulenberg JE; for the Inter-university Consortium for Political and Social Research. Monitoring the Future: a continuing study of american youth (12th-grade survey), 2005. 2007-07-18 ed. Ann Arbor, MI: Inter-university Consortium for Political and Social Research [distributor]; 2006:. Available from: http://dx.doi.org/10.3886/ICPSR04536. Accessed June 25, 2011.

52. Riley AW, Forrest CB, Starfield B, Green B, Kang M, Ensminger M. Reliability and validity of the adolescent health profile-types. Med Care. 1998;36(8):1237-1248.

53. Riley AW, Green BF, Forrest CB, Starfield B, Kang M, Ensminger ME. A taxonomy of adolescent health: development of the adolescent health profile-types. Med Care. 1998;36(8):1228-1236.

54. National Survey of American Life Self-Administered Questionnaire (NSAL-SAQ), February 2001-June 2003 [computer program]. Inter-university Consortium for Political and Social Research (ICPSR) [distributor]; 2010.

55. Cameron AC, Trivedi PK. Regression Analysis of Count Data. Cambridge, NY: Cambridge University Press; 1998.

56. Stata. Stata 10 Complete Documentation Set. College Station, TX: STATA press; 2007.

57. Barrionuevo A. In tangle of young lips, a sex rebellion in Chile. The New York Times. 2008 Sep 13; Sect. A:1.
Substance Abuse and Rehabilitation

\section{Publish your work in this journal}

Substance Abuse and Rehabilitation is an international, peer-reviewed, open access journal publishing original research, case reports, editorials, reviews and commentaries on all areas of addiction and substance abuse and options for treatment and rehabilitation. The manuscript management system is completely online and includes a very quick and

\section{Dovepress}

fair peer-review system. Visit http://www.dovepress.com/testimonials. php to read real quotes from published authors. 